\title{
Study on the Strategy of Enhancing the Spatial Vitality of Streets in Historical Districts - Fengxiang as an Example
}

\author{
Huang Xiaoyan, Miao $\mathrm{Li}^{*}$ \\ School of Architecture and Art, Dalian University of Technology, Dalian, China \\ Email address \\ Xiaoyan20210920@163.com (Huang Xiaoyan), miaoli@dlut.edu.cn (Miao Li) \\ ${ }^{*}$ Corresponding author
}

\section{To cite this article:}

Huang Xiaoyan, Miao Li. Study on the Strategy of Enhancing the Spatial Vitality of Streets in Historical Districts - Fengxiang as an Example. Science Discovery. Vol. 9, No. 5, 2021, pp. 213-218. doi: 10.11648/j.sd.20210905.13

Received: September 10, 2021; Accepted: September 29, 2021; Published: October 12, 2021

\begin{abstract}
As the main carrier of the evolution and development of historic districts, streets are the important foundation of street space, architectural texture and neighborhood vitality. However, in recent years, due to the inappropriate way of protecting the historic district and the rapid development of motorization, the spatial quality of the streets in the historic district has been declining and the vitality of the district has suffered a great impact. Located in Fengxiang District of Baoji City, Fengxiang Historic District has insufficient neighborhood vitality and poor spatial quality. In order to improve the vitality of the neighborhood and optimize the spatial quality of the neighborhood, we take "Wenchangxiang-Tongwenxiang-Feltersxiang Historic District" and "Xinzhuangxiang Historic District" in Fengxiang District as examples through a combination of qualitative description and quantitative analysis, and examine the causes of the lack of vitality of the neighborhood in terms of economy, culture and environment. The reasons for the lack of vitality of the neighborhoods are explored from three aspects. Finally, we propose the strategy to improve the vitality of the neighborhoods by upgrading the commercial space and creating diversified business modes, exploring the cultural connotation and forming regional linkage, and optimizing the neighborhood environment and strengthening the neighborhood management.
\end{abstract}

Keywords: Fengxiang, Historic District, Street, Vitality

\section{历史街区街道空间活力提升策略研究——以凤翔为例}

黄晓艳, 苗力*

大连理工大学建筑与艺术学院, 大连, 中国

邮箱

Xiaoyan20210920@163.com（黄晓艳）, miaoli@dlut.edu.cn（苗力）

摘要：街道作为历史街区演变和发展的主要载体，是街廓空间、建筑肌理和街区活力的重要基础。但近年来，由于历 史街区保护方式不当以及机动化的快速发展，历史街区街道空间品质不断下降，街区活力受到了巨大冲击。凤翔历史 街区位于宝鸡市凤翔区, 街区活力不足、空间品质不佳。为提高街区活力、优化空间品质, 通过定性描述与定量分析 相结合的研究方法，以凤翔区的 “文昌巷-通文巷-毡匠巷历史街区”与 “新庄巷历史街区” 为例，从经济、文化、环 境三个方面探析街区活力不足的原因。最后，提出 “升级商业空间，打造多元业态; 挖掘文化内涵，形成区域联动; 优化街区环境，加强街区管理”的街区活力提升策略。

关键词: 凤翔, 历史街区, 街道, 活力 


\section{1. 引言}

历史街区是一个城市成长的印记, 它承载着城市发展 的历史信息、特色风貌和生活方式，且历史街区大多位于 城市空间格局的重要位置[1]。街道空间作为街区发展的载 体, 不仅传承着历史文化内涵, 更承担着日常出行、交通 运输、旅游等多重复合功能[2], 对街区活力有着重要影响。 街道有生气，城市才有活力[3]。但随着社会的发展和现代 化的推进, 历史街区街道空间出现功能混杂、商业衰败等 问题, 严重影响了街区活力与空间品质。如何在存量更新 的前提下准确找到街道发展所存在的问题, 并由此创造出 新的街道活力是当前古镇及历史街区发展的重要课题[4]。

早期, 定性分析是街道活力研究的主要方法 [5], 近年 来, 随着大数据技术的兴起, 街道活力的研究趋向定量化。 以龙瀛团队为代表的学者们为大数据技术在街道活力研 究中的应用起到了重要的推动作用, 为历史街区街道空间 活力研究提供了新思路。另一方面, 当前历史街区街道活 力研究多关注特定要素对历史街区活力的贡献, 部分学者 借助网络开源数据探讨了多要素对历史街区活力分布的 影响, 但仍存在数据精度不够、活力表征要素单一 (多侧 重以 “人群活动密度” 来表征街道活力) 的问题[6]。基于 此, 本文将以风翔历史街区为例, 利用实地调研与大数据 技术相结合的方法, 测度街区街道活力分布现状, 进而探 究影响活力的具体因素, 并提出相应的街区活力提升策略。

\section{2. 凤翔历史街区概况}

\section{1. 研究区域}

本文研究区域位于陕西省宝鸡市凤翔区, 凤翔是陕西 省首批公布的省级历史文化名城, 历史悠久。古称 “雍”, 先秦19位王公在此建都294年, 是秦始皇加冕、苏轼初仕 之地[7]。2020年4月17日，凤翔区境内的 “文昌巷-通文巷 一轳匠巷历史文化街区” 和 “新庄巷历史文化街区” 被确 立为省级历史文化街区[8]。因这两个街区毗邻, 因此本文 的空间研究范围确定为两个历史街区街巷尽端边界所包 围的区域, 本次研究的街道为文昌巷、通文巷、段匠巷和 新庄巷（图1）。

\section{2. 街区现状价值}

凤翔历史街区现存有不少历史遗存, 省级重点文物保 护单位秦穆公墓位于街区内䏨匠巷与文化路交叉口, 其外 围高墙加筑, 不对外开放。文昌巷内有保存完整的北方典 型民宅一一周家大院, 现为县级重点文物保护单位, 免费 对外开放, 屋内展示有风翔传统手工艺品, 对街区活力的 提升起到了积极的影响。凤翔区博物馆和文化馆位于街区 附近的文化路北侧。风翔历史街区周边还有三佳购物广场、 时代广场、凤凰城商业广场、东湖公园、学校、医院等公 共资源（图2）。其中，东湖公园极具历史渊源，苏轼出 任凤翔府判官时, 曾疏浚东湖[9]。东湖现作为免费公园供 市民游咊, 园内建有苏公祠、亦有苏轱所修筑的喜雨亭, 文化价值颇高, 在当地有一定影响力。

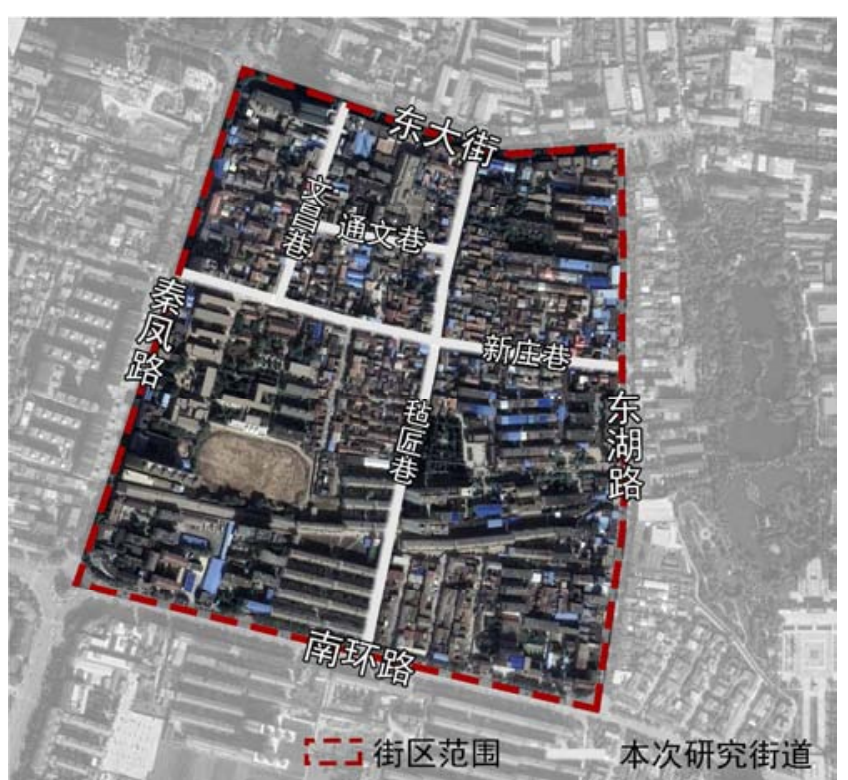

图1 研究范围（图片来源：笔者自绘）

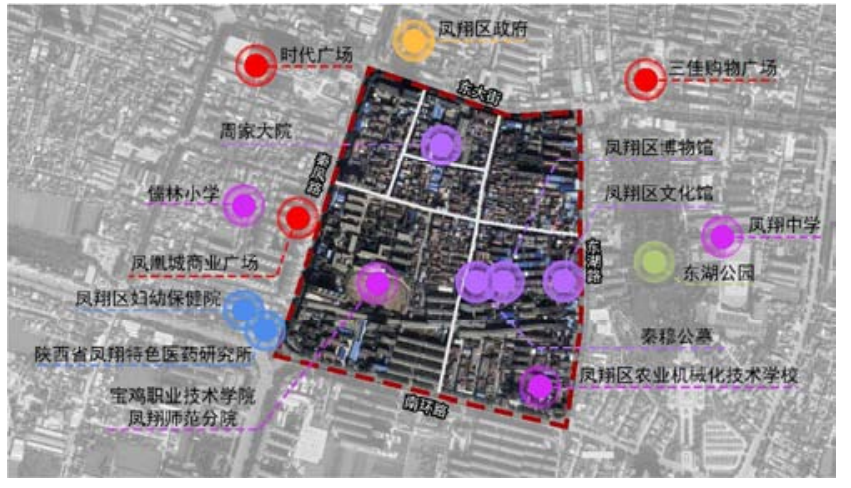

图2 研究区域周边环境（图片来源：笔者自绘）。

\section{3. 街区活力的概念及案例街区活力现状}

\section{1. 街道活力的概念}

城市领域的“活力”概念最初由国外学者提出, 其中, 凯文·林奇、伊恩·本特利等强调城市空间与功能的多样性, 提出活力包含 “具有多样化的公共空间, 多种使用功能的 特性”。而简.雅各布斯和扬·盖尔等多强调城市中人的活 动的多样性, 认为城市的活力源于在其中的人以及人们的 活动[10]。空间是人活动的载体, 多样化的街道空间能够 吸引人们聚集并产生一系列活动。而街道活力的核心在于 街道上从事各类活动的人 $[11]$ 。人的聚集、生活使城市有 了生命体的特征, 是城市活力产生的动因。因此, 本文将 街道活力定义为街道空间的多样化以及人流的集聚度。

\section{2. 凤翔历史街区活力现状}

百度热力图是百度公司推出的一款大数据可视化产 品, 该产品以LBS平台手机用户地理位置数据为基础, 基 于智能手机使用者访问百度产品（如搜索、地图、天气和 音乐等) 时所携带的位置信息, 按照位置聚类, 计算各地 
区内聚类的人群密度和人流速度, 计算结果用不同的颜色 和亮度反映人流量的空间差异[12]。百度热力图具有直观 反映地区人流量聚集情况的优点, 随着大数据技术的发展, 已被广泛应用于城市活力的研究中[13]。笔者采集了2021 年8月 28日6:00-20: 00 (间隔一小时) 的热力图, 根据 历史街区的热力图可以看出, 街区内部活力点较少, 上午 8：00-12: 00, 街区内部主要街巷无明显活力点。下午两 点, 毡匠巷人流较多, 吸引点主要为餐馆、美发店等, 下 午四点, 街区东北方向的恒源商厦、东南方向的文具店、 小吃店出现活力点。晚上六点至八点, 活力点主要集中在 秦凤路, 街区内部无明显活力点 (图3)。

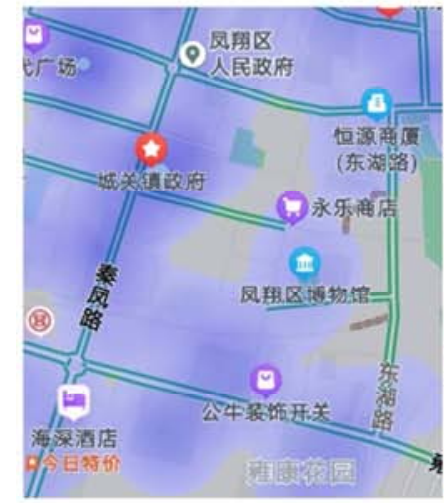

6: 00

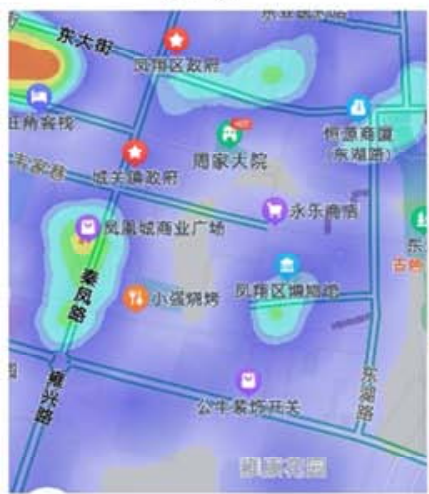

14: 00

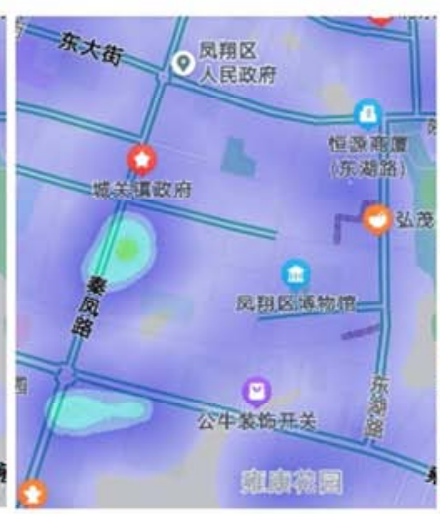

8: 00

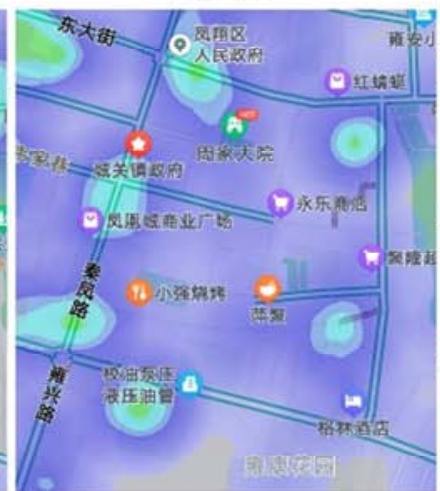

16: 00

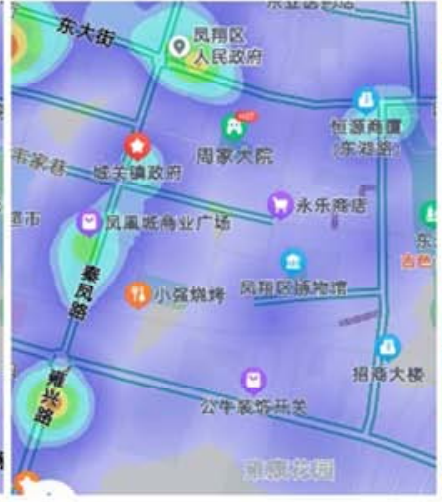

10: 00

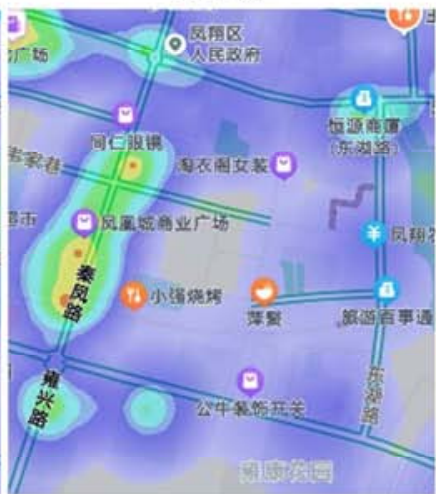

18: 00

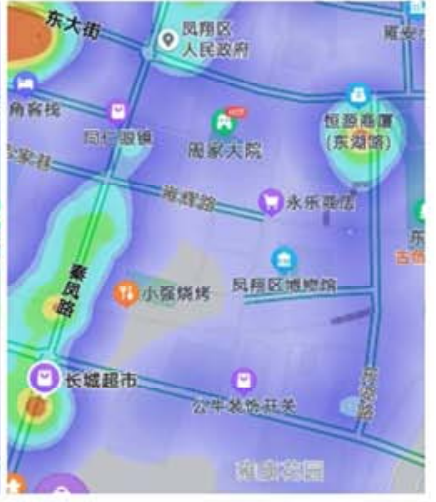

12: 00

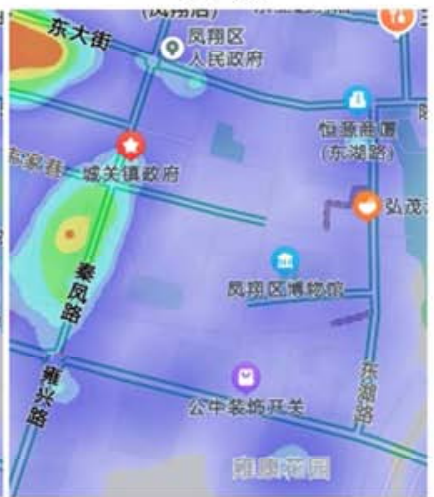

20: 00

图3 街区百度热力图（图片来源：笔者整理）。

\section{4. 街区活力不足的原因}

城市活力与其经济状况有着密不可分的关系, 历史街 区作为城市的一部分, 其活力也与街区经济繁荣度息息相 关。经济活力作为街区活力产生的前提, 主要体现在街区 本身具备的竞争力及对外部资源的吸引力 [14], 丰富多元 的商业业态对人流有一定的吸引作用。另一方面, 历史街 区又因其独特的历史文化遗存而区别于城市其他区域, 如 果说经济活力是街区活力的外在表征, 那么文化活力就是 街区活力的内涵。再者, 历史街区的环境状况也对人们在 街区活动的舒适度有着重要影响。良好的商业环境能够吸 引消费者, 促进居民回购。物质环境的改善也能够促使人 们在空间中停留并产生一系列活动, 从而为街区带来活力。
因此, 本文将历史街区活力的影响因素分为经济因素、文 化因素以及环境因素三方面。

\section{1. 经济因素}

丰富多元的商业业态是经济活力的重要基础, 功能混 合度与功能密度可以衡量街道商业业态的丰富性与集聚 度。因此, 本文使用街道的功能混合度与功能密度来表征 街道的经济活力。

\subsection{1. 功能混合度}

街道功能混合度指街道周边与活力相关的POI混合度, 可用信息熵来计算。

$$
\text { Diversity }=-\operatorname{sum}(p i \times \ln p i),(i=1, \ldots, n)
$$


式中 Diversity 表示某街道的功能混合度, $\mathrm{n}$ 表示该 街道POI的类别数, $\mathrm{pi}$ 表示某类POI占所在街道POI总数的 相对比, 各类POI数量均进行过归一化处理[15]。

\subsection{2. 功能密度}

街道功能密度即街道周边 (通常取道路中心线 $55 \mathrm{~m}$ 缓 冲范围内) 与活力相关的兴趣点 (Point of Interest, POI) 密度 [16]。能够反映街区商业业态的密集程度与连续性。 因本文研究范围较小, 因此将缓冲范围定位 $50 \mathrm{~m}$ 。

$$
\text { Density = POI_num /road_length }
$$

式中Density表示某街段的功能密度, POI_num表示该 街段缓冲范围内影响活力的POI总数, road_length表示该 街段的长度[15]。

利用高德地图API爬取到POI数据, 获取时间为 2021 年8月, 该数据包含餐饮服务、购物服务、生活服务、休 闲服务、住宿服务和名胜古迹 6 大类，共计 124 个 (表 1 )。 考虑到历史文化街区的特性, 在用地性质上需要进行细分, 比如餐饮、零售在城市用地分类中均属于商业用地, 在此 视为两种不同的功能。

表1 街道POI分类表（数据来源：笔者整理）。

\begin{tabular}{ll}
\hline 一级分类 & 二级分类 \\
\hline 餐饮类 & 中餐厅、小吃店、糕饼店、饮品店 \\
住宿类 & 酒店、宾馆、招待所 \\
游览类 & 演艺娱乐、文化展览、文人故居、宗教祠堂 \\
购物类 & 服装鞋包、超市商场、工艺饰品、旅游商品 \\
休闲类 & KTV、彩票店、俱乐部、健身房、网咖、酒吧、棋牌室、影剧院、电竞馆、桌球室 \\
生活类 & 影楼、理发店、美容会所、打印店、洗浴中心 \\
\hline
\end{tabular}

表2 街巷功能混合度与功能密度统计表（表格来源：笔者整理）。

\begin{tabular}{|c|c|c|c|c|}
\hline \multirow{2}{*}{ 分析单元 } & \multicolumn{4}{|l|}{ 主要街巷名称 } \\
\hline & 毡匠巷 & 通文巷 & 文昌巷 & 新庄巷 \\
\hline POI种类 & $\begin{array}{l}\text { 餐饮、购物、住宿、生活、游览、 } \\
\text { 休闲 }\end{array}$ & 餐饮、游览、住宿、生活 & $\begin{array}{l}\text { 餐饮、生活、购物、住 } \\
\text { 宿 }\end{array}$ & $\begin{array}{l}\text { 休闲、游览、生活、购物、餐 } \\
\text { 饮 }\end{array}$ \\
\hline POI数量 & $\begin{array}{l}\text { 餐饮*8+购物*6+住宿*4+生活* } 12+ \\
\text { 游览* } 1+\text { 休闲*3=46 }\end{array}$ & $\begin{array}{l}\text { 餐饮*12+购物*9+住宿*2+生活 } \\
* 8=31\end{array}$ & $\begin{array}{l}\text { 餐饮*3+住宿*3+生活 } \\
* 2+\text { 游览*1=9 }\end{array}$ & $\begin{array}{l}\text { 餐饮*9+购物*8+住宿*5+生活 } \\
* 13+\text { 游览*3=38 }\end{array}$ \\
\hline 功能混合度 & 1.496 & 1.253 & 1.311 & 1.503 \\
\hline 功能密度 & $46 / 4960=0.0093$ & $31 / 2062=0.0150$ & $9 / 1478=0.0061$ & $38 / 4351=0.0087$ \\
\hline
\end{tabular}

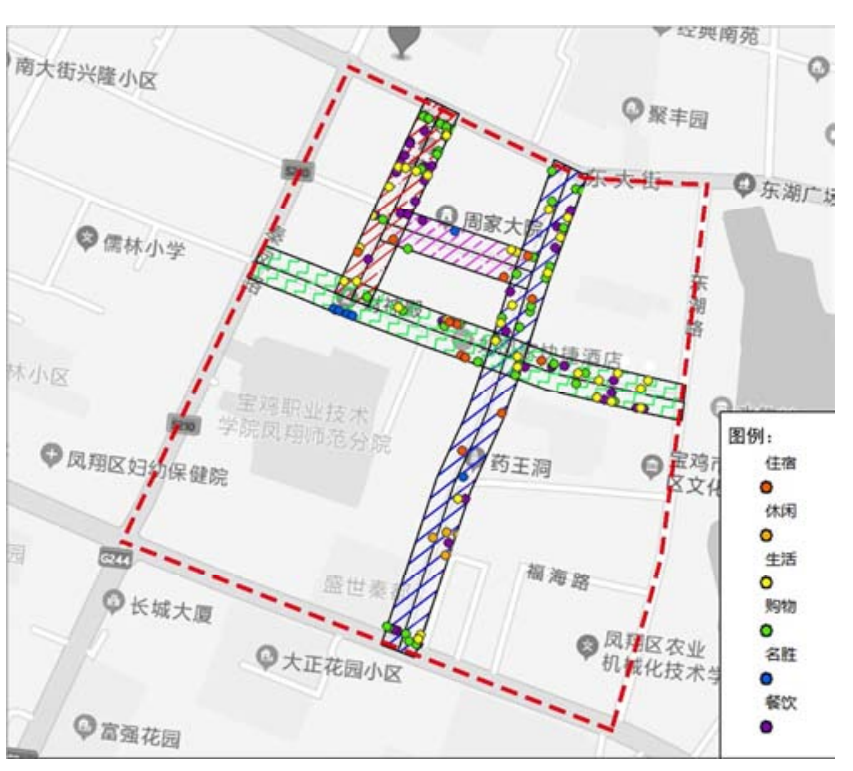

图4 主要街巷50米缓冲范围内的POI分布（图片来源：笔者自绘）。

综合图4和表 2 可以看出, 文昌巷与通文巷功能混合度 较低, 业态较为单一, 新庄巷与毡匠巷功能混合度较高, 但功能密度较低, 商业空间不连续, 降低了行人步行体验, 导致街巷较为冷清、缺乏活力。

\section{2. 文化因素}

通过现状调研发现, 街区对风翔历史文化的内涵挖掘 不够，仅仅对物质层面进行了简单的改造: 提取与凤翔文 化不相关的花卉元素对街巷两侧建筑进行墙面进行装饰, 使用仿古路灯（图5）。街区内现存有2处历史遗存一一周 家大院与秦穆公墓, 3 处县级祠堂, 但损毁严重。周家大 院现已作为小型民俗博物馆供游客参观。秦穆公墓由于性 质特殊被封闭管理。总之, 街区的文化浮于表面, 街巷指 示标识与周家大院的指示标识风格迥异, 未充分挖掘风翔 文化特色, 文化内涵流失严重。

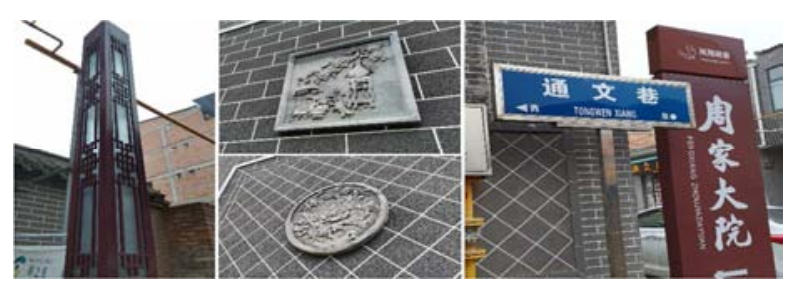

图5 浮于表面的文化符号（图片来源：笔者拍摄）。

\section{3. 环境因素}

\subsection{1. 商业环境}

空间是供人使用的, 生活在其中的人们心理体验上的 舒适度是衡量空间好坏的重要参考。本文通过爬取大众点 
评的点评内容来分析居民体验, 共爬取到 1522 条有效数据, 然后对点评内容进行词频分析（图6）。分析发现，周家 大院的评分最高, 点评高频词为 “周家、身份证”, 通过 查阅点评内容, 了解到周家大院只需刷身份证即可免费参 观。新庄巷内店铺多为餐馆和酒店, 有 8 家农家乐, 最大 的优点是环境好, 但餐馆味道一般; 文昌巷内店铺评价普 遍较好, 但部分商铺卫生状况堪忧; 毡匠巷点评内容有 “热 情、干净、新鲜、便宜” 等正向词汇, 但消费者一致认为 店铺过于偏僻、不便寻找。针对店铺过于偏僻, 笔者经实 地调研发现, 许多商铺均为居民自家房屋改造而成, 容易 与其他居民房屋混淆，因此不便寻找。

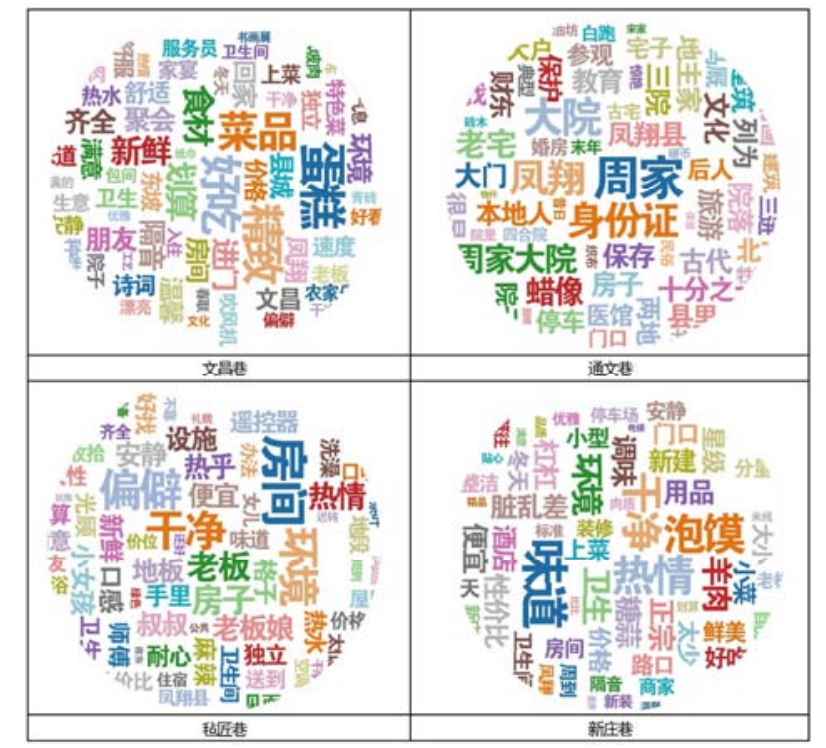

图6 主要街巷店铺大众点评词云图（图片来源：笔者自绘）。

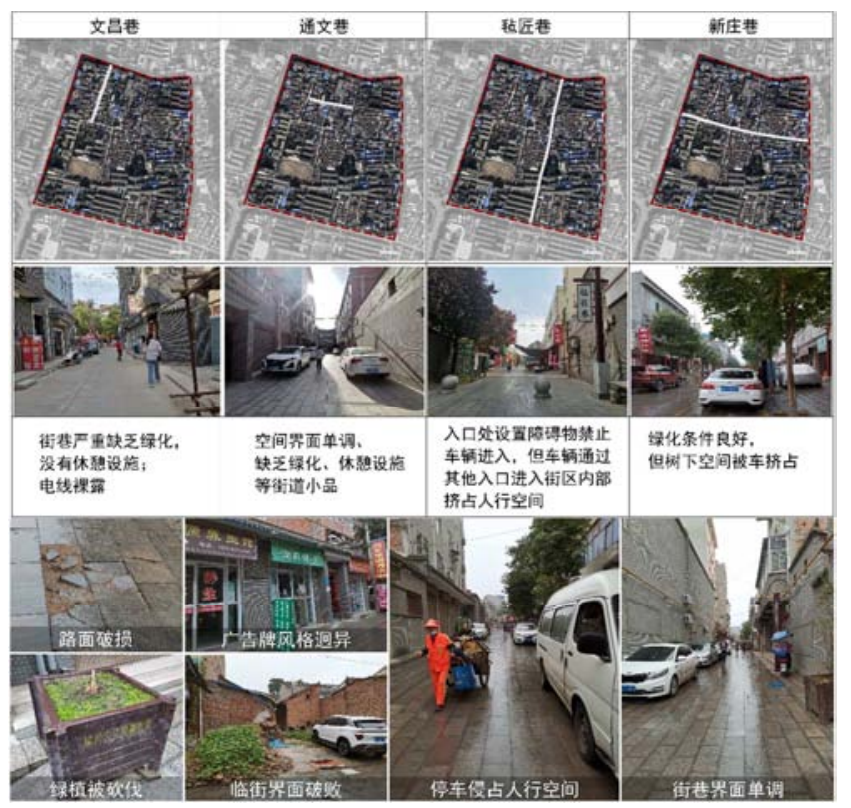

图7 街区物质环境现状（图片来源：笔者自绘）。

\subsection{2. 物质环境}

街区内部多处路面破损，广告牌色彩、风格迥异，毡 匠巷临街界面不连续, 出现房屋坍塌的问题。景观绿化方
面, 新庄巷单侧种植有行道树, 树径较大, 能起到遮荫纳 凉的作用, 但树下空间多被汽车霸占, 行人难以使用。毡 匠巷和通文巷仅有三四棵居民门前种植的果树, 文昌巷和 通文巷内仅有少数灌木, 且部分灌木被砍伐。另外, 通文 巷街巷界面过于单调, 缺乏趣味性（图7）。另外, 街区 内部没有设置休鄎设施, 降低了人们出行的舒适度。

\section{5. 街区活力提升策略}

基于风翔历史街区现状问题与自身优势，笔者从 “升 级商业空间, 打造多元业态; 挖掘文化内涵, 形成区域联 动; 优化街区环境, 重焕街区活力” 这三个方面提出街区 活力提升策略:

\section{1. 升级商业空间, 打造多元业态}

现状历史街区商业业态以小型零售店、小吃店等为主, 业态较为低端。可基于凤翔特色引入老字号企业, 升级商 业业态, 形成品牌效应, 吸引人流。打造多元业态, 丰富 文昌巷与通文巷的商业业态, 在毡匠巷南段与新庄巷打造 更多商业空间, 增加街区的功能密度, 使商业空间连续, 提高人们的出行体验。

\section{2. 挖掘文化内涵, 形成区域联动}

挖掘风翔历史街区的文化内涵, 注重现有历史遗存的 保护, 统一街巷指示标识的风格。建立与周边区域的联系, 形成区域联动。街区地理位置优越, 可依托处于县城中心、 毗邻东湖公园的优势, 以新庄巷现有的 8 家农家乐为基础, 在新庄巷打造兼具风翔特色风味与先秦风格的综合美食 街区, 吸引东湖游客二次游览。

\section{3. 优化街区环境, 加强街区管理}

优化街区环境, 包括商业环境和物质环境两方面。商 业环境方面: 可定期举办街区厨艺大比拼活动, 通过奖惩 机制引导商家改良口味。通过统一化商铺门面, 使其与普 通居民房屋有所区别, 便于人们寻找。物质环境方面: 修 复破损路面; 统一广告牌的色彩、风格; 在建筑的退线空 间打造良好的交流场所; 增加街道绿化, 引入当地适宜存 活的树种, 为行人提供遮荫纳凉的步行空间。同时, 可结 合乔木设置树下座椅, 便于人们休礊停留。街区环境的衰 败主因在于街区管理的不到位, 应建立公众参与机制, 引 导街区居民强化自我管理、自我监督意识, 加强街区管理。

\section{6. 结论}

本文通过借助百度热力图、实地踏勘的方式了解凤翔 历史街区现状活力情况, 发现街区内部活力不足、空间品 质欠佳。随后从经济、文化、环境三个方面来分析街区活 力不足的原因。经济方面, 街区内文昌巷、通文巷功能混 合度较低、业态较为单一, 毡匠巷与新庄巷功能混合度较 高、但功能密度偏低, 商业界面不连续。文化方面, 现状 历史街区尚未挖掘凤翔历史文化内涵, 仅提取简单的文化 符号对墙面进行装饰。环境方面, 通过大众点评数据了解 
到街区商业环境总体较好, 但存在菜品味道一般、商铺过 于偏僻的问题; 另外, 街区物质环境较差, 存在路面破损、 缺乏绿化景观等街道小品、停车占道、街道界面单调等问 题。针对以上分析, 笔者从 “升级商业空间, 打造多元业 态; 挖掘文化内涵, 形成区域联动; 优化街区环境, 加强 街区管理”三个方面提出了街区活力提升策略。

历史街区活力的影响要素众多, 本文选取的经济、文 化、环境要素不足以解释所有历史街区街道空间活力状况。 但其对风翔历史街区街道活力的提升仍具有一定的现实 意义, 其研究思路与方法也适用于历史街区街道空间活力 的解析, 未来研究需要更多学科、地域的学者共同努力。

\section{参考文献}

[1] 尹衍群,陈坤,王英姿.基于空间句法与百度热力图综合测度 的历史街区活力研究 [J]. 中外建筑,2021(08):101-106.

[2] 赵雅芝. 基于街景地图的历史文化街区街道空间品质评价 [D]. 广州大学, 2019.

[3] Jacobs,J.The death and life of great American cities[M].New York:Random house, 1961.

[4] 张春明.多源数据下的古镇街道空间活力评价研究一一评 《城市规划大数据理论与方法评论》 [J]. 中国科技论 文,2020,15(04):509.

[5] 邢忠, 陈子龙, 顾媛媛, 等. 基于大数据的城市街道活力影 响因素定量分析 [J]. 西部人居环境学刊, 2021，36(3): 98-105.
[6] 毛志睿, 陈笑葵, 项振海, 等. 历史街区街道活力测度及 影响因素研究——昆明市文明街历史街区为例 [J]. 南方 建筑, 2021 (4): 48-55.

[7] 凤翔（陕西省宝鸡市辖区） [EB/OL]. 百度百科. https://baike.baidu.com/item/凤翔区/55939635.

[8] 陕西省人民政府关于公布第二批历史文化街区名单的通知 [EB/OL]. 陕西省人民政府．陕政函（2020５５2号 http://www.shaanxi.gov.cn/zfxxgk/zfgb/2020/d15q/202008/t2 0200817_1728559.html.

[9] 张文利.苏轼与凤翔东湖 [J].古典文学知识,2006(04):77-83.

[10] 盛况,高祥. 国外城市活力街区的实践浅析 [J]. 城乡建 设,2020(24):62-63.

[11] Mehta,V.Lively streets:Determining environmental characteristics to support social behavior[J].Journal of Planning Education and Research,2007,27(2):165-187.

[12] 王录仓.基于百度热力图的武汉市主城区城市人群聚集时 空特征[J].西部人居环境学刊,2018,33(02):52-56.

[13] 周晓曦,刘常静,陈春明,李薇薇,杨怡,周李偣. Spatiotemporal Characteristics of Vitality in the Central Area of Chongqing Based on Bai-du Heatmap[J]. 地理科学研究,2021,10(03).

[14] 孟运五, 吴运法.历史街区活力再生营造策略——合肥城 隍庙街区为例[J].华中建筑,2021,39(07):133-137.

[15] 龙瀛,周垠. 街道活力的量化评价及影响因素分析一以成 都为例 [J].新建筑,2016(01):52-57.

[16] 郝新华,龙瀛,石炎沝,王鹏.北京街道活力:测度、影响因素与规 划设计启示 $[J]$.上海城市规划,2016(03):37-45. 